\title{
Perceptions of Midwestern Crop Advisors and Growers on Foliar Fungicide Adoption and Use in Maize
}

\author{
P. D. Esker, ${ }^{\dagger}$ D. A. Shah, C. A. Bradley, S. P. Conley, P. A. Paul, and A. E. Robertson
}

First author: Department of Plant Pathology and Environmental Microbiology, Penn State University, University Park 16802; second author: Department of Plant Pathology, Kansas State University, Manhattan 66506; third author: Department of Plant Pathology, University of Kentucky Research and Education Center, Princeton 42445; fourth author: Department of Agronomy, University of Wisconsin-Madison, Madison 53706; fifth author: Department of Plant Pathology, The Ohio State University, Wooster 44691; and sixth author: Department of Plant Pathology and Microbiology, Iowa State University, Ames 50010.

Accepted for publication 12 April 2018.

\begin{abstract}
Foliar fungicide use in hybrid maize in the United States was rare before 2000. The decade from 2000 to 2010 saw foliar fungicides increasingly applied to maize in the absence of appreciable disease pressure, a practice seemingly at odds with integrated pest management philosophy. Yet, it is commonly believed that growers do not employ management strategies unless there are perceived benefits. Maize (corn) growers (CGs) and certified crop advisors (CCAs) across four Midwestern states (Iowa, Illinois, Ohio, and Wisconsin) were surveyed to better understand their practices, values and perceptions concerning the use of foliar fungicides during 2005 to 2009. The survey results demonstrated the rapid rise in maize foliar

time during 2005 to 2009 . During 2005 to $2009,73 \%$ of CCAs had recommended using a foliar fungicide, but only $35 \%$ of CGs sprayed. Perceived yield gains, conditional on having sprayed, were above the break-even point on average. However, negative yield responses were also observed by almost half of CCAs and a quarter of CGs. Hybrid disease resistance was a more important factor to economically successful maize production than foliar fungicides. Diseases as a yield-limiting factor were more important to CGs than CCAs. As a group, CGs were not as embracing of foliar fungicide as were CCAs, and remained more conservative about the perceived benefits to yield.
\end{abstract} fungicide applications from 2000 through 2008, with 84\% of CGs who sprayed having used a foliar fungicide in maize production for the very first

Plant diseases are perceived to be important but controllable risks (Lupo et al. 2016; Maye et al. 2012). The control point lies with growers and depends, in part, on the availability of fungicides (Ilbery et al. 2013). Fungicides against maize foliar diseases have been available in the United States for several decades, but before 1980 maize diseases were considered low-risk (Latterell and Rossi 1983). Indeed, even up to 1998 foliar fungicide use in U.S. maize was rare (Vincelli 1999), and only profitable in hybrid maize seed production (Wegulo et al. 1997). At that time, Extension and crop advisors predicted no appreciable change in fungicide use over the next five years, because crop rotation and hybrid resistance would continue providing economically acceptable levels of disease control (Vincelli 1999). However, with shifts to shorter rotations and reduced forms of tillage, residue-borne diseases began to appear more frequently (Jirak-Peterson and Esker 2011; Paul and Munkvold 2004; Romero Luna and Wise 2015; Wegulo et al. 1998). In particular, gray leaf spot (incited by Cercospora zeae-maydis) was propelled (as predicted [Latterell and Rossi 1983]) from the sideline to international status (Lipps 1998; Ward et al. 1999). Increased risk of maize foliar diseases was also coupled to the uncertainty of predicting outbreaks (Paul and Munkvold 2005). Additionally, the decade beginning with the year 2000 saw increasing maize prices, the registration of quinone outside

${ }^{\dagger}$ Corresponding author: P. D. Esker; E-mail: pde6@psu.edu

Funding: This research was funded by USDA-NIFA-RAMP grant 2009-5110105820 .

*The $\boldsymbol{e}$-Xtra logo stands for "electronic extra" and indicates that one supplementary file is published online.

(C) 2018 The American Phytopathological Society
Additional keywords: dual-frame survey, strobilurin fungicides inhibitor (QoI; strobilurin) fungicides for maize, a large inventory of available fungicide products, and new marketing promoting plant health benefits of QoI-based fungicides even in the absence of appreciable disease (Werts and Green 2013; Wise and Mueller 2011). By 2007 approximately $10 \%$ of maize in the United States was being sprayed with foliar fungicides, and that number was projected to increase yearly (Wise and Mueller 2011). For the year 2010, the Agricultural Resource Management Survey (ARMS; https:// www.ers.usda.gov/) estimated that $22.5 \%$ of the planted maize area in Illinois was treated with fungicides.

Concern began to appear among plant pathologists that the increasing use of fungicides in maize, even (or especially) in the absence of significant disease pressure, was a violation of core integrated pest management (IPM) principles (Wise and Mueller 2011), and made even less sense given that multiple university trials across the U.S. Corn Belt had shown inconsistent profitability under low foliar disease severity (Bradley and Ames 2010; Mallowa et al. 2015; Paul et al. 2011; Romero Luna and Wise 2015; Wise and Mueller 2011). Therefore, the recently adopted practice of spraying maize with foliar fungicides appeared to be irrational. Yet growers are strongly pragmatic (Ilbery et al. 2012), and gravitate to costeffective strategies that minimize financial risk (Zalucki et al. 2009). Thus, it is very unlikely that they would engage in spraying foliar fungicides without a perceived benefit.

Perceptions of diseases and their management do transition over time (McRoberts et al. 2003), and it is possible that forces (e.g., maize demand and price) may have driven a perceptional evolution on the role of fungicides in maize production. Quite possibly, the practice of using foliar fungicides in maize may have evolved to the point where it is divorced from IPM principles (Bradley 2012; Wise and Mueller 2011). Management decisions are made by maize (corn) growers (CGs) themselves, or by certified crop advisors (CCAs) hired by CGs. One may hypothesize that CGs and CCAs 
have updated their belief system to foliar fungicides being required for successful maize production, from the previous belief that foliar fungicides were mainly unnecessary.

The perceptions of CGs and the CCAs who advise them with regard to maize production have been surveyed only briefly in the past, and with very small sample sizes (Bradley 2012; Vincelli 1999). Bradley (2012) reported that in 2008 in Illinois 63\% of survey respondents applied or had recommended applying a foliar fungicide to maize. Disease pressure was one of the major factors influencing the decision to spray, but tellingly $14 \%$ of respondents considered the potential for higher yields to be the most important factor in their decision to spray. In the current article, we addressed the maizefungicide issue from the perspective of CCAs and CGs in four Midwestern states by surveying their perceptions, observations, and practices with respect to fungicides within maize production.

\section{MATERIALS AND METHODS}

Survey administration. The target populations were CGs and CCAs in four Midwestern states: Ohio (OH), Illinois (IL), Iowa (IA) and Wisconsin (WI). The survey questionnaire was designed and administered in Spring 2010 by the University of Wisconsin Survey Center (UWSC), with input from P. D. Esker, C. A. Bradley, P. A. Paul, and A. E. Robertson. The study's protocol (Protocol Number: SE-2010-0188) was approved by the Institutional Review Board at the University of Wisconsin-Madison. Participants' consent was documented by the return of surveys; those who chose to exercise their right to not participate simply did not complete or mail the survey back to the UWSC. There were two versions of the self-administered questionnaire: one version was sent to CCAs, and the other version was mailed to CGs. The two versions overlapped in content, with additional questions tailored specifically to each of the two target populations. There were 53 questions on the CCA questionnaire, whereas the CG version had 48 questions. Questions were within five broad categories: (i) general maize production practices and farm management, (ii) perceptions of diseases and their importance in maize production, (iii) the role of fungicides in successful maize production, (iv) IPM-type activities, with a focus on scouting for diseases in decision-making, and (v) sources and types of information used or consulted when making decisions about maize diseases and their management. The target samples were 188 CCAs and 188 CGs in each of the four states, for a target of 1,504 individuals total.

The UWSC used a three-wave data collection protocol. Wave 1 was a full packet mailing to all 1,504 individuals of the target sample (cover letter, business reply envelope, US\$2-dollar bill pre-incentive, and 12-page survey) on 16 April 2010. Wave 2 was a postcard reminder sent on April 19, 2010. Wave 3 was a full mailing on 17 May 2010 to 950 eligible individuals who had not yet participated. Respondents mailed the self-completed surveys back to the UWSC in the postage-paid envelopes. The UWSC received responses between 20 April 2010 and 15 July 2010. Of the 682 completed surveys returned, $75 \%$ were returned following the first mailing and postcard, while the other $25 \%$ were returned in response to the second survey mailing. The overall response rate was $47.4 \%$ (52.1\% for CCAs and $42.4 \%$ for CGs). There were 370 eligible completed surveys from CCAs and 295 from CGs. Trained data entry operators at the UWSC produced two final, processed data sets output as SPSS.sav files, one for each of the sampled groups. Data were analyzed anonymously (each participant was tracked only by a case identification number assigned by the UWSC).

Data preparation and analysis. The $\mathrm{R}$ system (64-bit version 3.0.2; R Foundation for Statistical Computing, Vienna) running on Windows 7 Professional ((Microsoft Corp., Redmond, WA) was used as the programming and analytical environment. The SPSS files were read into R, after which further checks on data integrity were performed. Every observation row of the CCA and CG data sets had at least one missing datum value. The approaches of either (i) removing rows with missing data (complete-case analysis), or (ii) using two-phase estimation (Heeringa et al. 2010; Lumley 2010), which requires a subset of individuals with complete data, were therefore not viable options with these survey data. We instead used multiple imputation, which is a form of stochastic imputation (Rubin 1987), to estimate reasonable values for the missing data. In multiple imputation, the missing values are filled in with estimates to create a complete (no missing values) data set. This process is repeated to create $m$ independent, complete data sets, where the differences across the $m$ sets reflect the uncertainty in the estimated values. The $m$ data sets are then each analyzed separately but identically. In the final step, the coefficients and standard errors are combined for inference (Rubin 1987). Ten imputed versions each of the CCA and CG data sets were created using the multiple imputation by chained equations algorithm (White et al. 2011). Post-imputation data checks were done to confirm that imputation models converged, that imputed values were within distributional ranges (e.g., via histograms and scatterplots), and that imputed values respected any bounds or constraints inherent to the data. Imputations and post-imputation data checks were done with the mice package, version 2.21 (van Buuren and GroothuisOudshoorn 2011).

The CCA and CG survey data sets were combined on questions common to both to create a dual-frame sample (Groves and Lepkowski 1985). Because there was no overlap in the frames (i.e., no one was both a CCA and a CG), the dual-frame estimators reduced to the same estimators obtained with a sample consisting of two strata. The sample weights (described later) remained the same, and were not affected by combining the surveys. The combined CCA-CG sample allowed for the comparison and modeling of responses to common questions.

The populations of interest (i.e., on which inferences were desired) were CCAs and CGs in IA, IL, OH, and WI. Estimates based on the raw data (e.g., a mean response calculated over all 295 returned CG questionnaires) are an incorrect way of obtaining statistics from survey data (Heeringa et al. 2010; Kish 1965). This is because each sampled individual represents a certain proportion of the target CCA and CG populations, which are of course different among the four states. Therefore, one must account for the finite populations that were surveyed, and how many individuals in the populations were represented by each survey response, for the correct calculation of point estimates and standard errors. The CCA populations were estimated from lists of registered members in each state (https://www.certifiedcropadviser.org/). The CG populations were estimated from the 2007 Census of Agriculture, Farm Typology data (National Agricultural Statistics Service). The population estimates were used together with the number of eligible completed surveys (Table 1) to calculate survey response weights for CCAs and CGs in each state.

TABLE 1. Population estimates and number of eligible completed surveys for maize growers and certified crop advisors

\begin{tabular}{lcc}
\hline State & $\begin{array}{c}\text { Population } \\
\text { estimate }^{\mathrm{a}}\end{array}$ & $\begin{array}{c}\text { Eligible completed survey } \\
\text { responses }\end{array}$ \\
\hline Maize growers (CGs) & & \\
$\quad$ Iowa & 49,970 & 59 \\
$\quad$ Illinois & 38,668 & 52 \\
Ohio & 24,006 & 80 \\
$\quad$ Wisconsin & 24,112 & 104 \\
Certified crop advisors & & \\
(CCAs) & 929 & 82 \\
Iowa & 1,023 & 87 \\
Illinois & 373 & 92 \\
Ohio & 482 & 109 \\
Wisconsin &
\end{tabular}

${ }^{a}$ CG population estimates were obtained from the U.S. 2007 Census of Agriculture, Farm Typology data (National Agricultural Statistics Service). CCA estimates were obtained from registered member lists for each state. 
The survey design was described to the survey package (Lumley 2004) version 3.29-5, which was used in conjunction with the mitools package (version 2.2) to obtain point estimates and standard errors corrected for both the survey design and the additional variance introduced by imputation. Estimates were visualized graphically with the lattice (version 0.20-27) and latticeExtra (version 0.6-26) packages (Sarkar 2008). Estimated proportions were presented as percentages on the full (i.e., 0 to 100) scale to facilitate comparisons across graphs or panels, and to avoid the exaggeration of small, nonpractical differences.

The current article analyzed a subset of the survey questions focused on the perceptions of CCAs and CGs with respect to the importance of different biotic, economic and agronomic factors to successful maize production, their involvement in on-farm trials, foliar fungicide practices during 2005 to 2009, and the perceived benefits (to yield) of foliar fungicides. Yield-related questions were framed in terms of bushels per acre (bu/A), as U.S. CCAs and CGs are comfortable and familiar with working in those units. For the analysis and presentation of results, yield-related data were converted to metric tons per hectare $(1 \mathrm{bu} / \mathrm{A}=0.0628 \mathrm{t} / \mathrm{ha})$. The questions are briefly described below; Supplementary File S1 presents the questions formatted as they appeared in the mailed questionnaires. The first question of the subset we analyzed asked CCAs and CGs about the importance of biotic agents (weeds, insects, diseases) to the maize yield losses they perceived. The second (multipart) question asked about the importance of several agronomic and economic factors (commodity prices, seed price per bag, corn plant populations, crop rotation, tillage, previous crop history and yield, maximizing yield, maximizing profit, disease resistance, new herbicides, foliar applied insecticides, foliar applied fungicides, other factors [e.g., use of Roundup Ready or Bt maize]) in successful maize production. Possible responses to these first two questions were on a five-level ordered categorical (ordinal) scale: "Not at all important", "Slightly important", "Somewhat important", "Very important", "Extremely important". For some of these questions, the five response categories were collapsed to three ordinal categories ("Low importance" = "Not at all important" or "Slightly important"; "Intermediate importance" = "Somewhat important"; "High importance" = "Very important"; or "Extremely important") for model stability during estimation, because of low proportions when the data were spread across five categories. Questions 3 to 6 asked whether on-farm research trials were done in 2009 ("Yes" or "No"), and if done, what types of trials were coordinated (hybrid, seed treatment, herbicide, insecticide or foliar fungicide trials), whether these trials included treatment replication, and if so, how many replicates on average. Questions 7 through 10 addressed the use of foliar fungicides in maize production: whether foliar fungicides had been recommended (by CCAs) or used by CGs ("Yes" or "No") in maize fields in the past five (2005 to 2009) growing seasons, and if so, the type of crops sprayed (maize for grain, seed, or silage), the first year in which fungicides were used in hybrid maize production, and the active ingredients used (Headline [BASF Corporation], Quilt [Syngenta], Stratego [Bayer], or Quadris [Syngenta]). Questions 11 to 12 asked whether a positive yield response had been realized with the application of a foliar fungicide to maize ("Yes" or "No"), and if so, what the average yield gain was (less than $1 \mathrm{bu} / \mathrm{A}, 1$ to $4 \mathrm{bu} / \mathrm{A}, 5$ to $9 \mathrm{bu} / \mathrm{A}, 10$ to $14 \mathrm{bu} / \mathrm{A}$, or greater than $15 \mathrm{bu} / \mathrm{A})$. In contrast, questions 13 to 14 asked whether a negative yield response had been experienced with the application of a foliar fungicide to maize ("Yes" or "No"), and if so, the average negative response (greater than $15 \mathrm{bu} / \mathrm{A}, 10$ to $14 \mathrm{bu} / \mathrm{A}, 5$ to $9 \mathrm{bu} / \mathrm{A}$, 1 to $4 \mathrm{bu} / \mathrm{A}$, or less than $1 \mathrm{bu} / \mathrm{A})$. Question 15 asked CCAs and CGs about how much they were willing to spend (US\$) per acre on foliar fungicides in 2009 (less than $\$ 15, \$ 15$ to $\$ 19, \$ 20$ to $\$ 24, \$ 25$ to $\$ 29, \$ 30$ or more). Finally, question 16 asked if in 2009 untreated check strips were used in maize fields sprayed with foliar fungicides, and if so, to indicate how many and where in the field they were placed.
In addition, another section of the questionnaire was designed to gather information on CCA and CG age demographics and educational achievement. There were five response categories for age: 24 or younger, 25 to 34,35 to 44,45 to 54 , and 55 or older. The proportions in the 24 or younger age cohort were negligible. For the purposes of this analysis, the age cohorts were collapsed to three categories: (i) 34 or younger (i.e., combine the 24 or younger and 25 to 34 cohorts); (ii) 35 to 54 (i.e., combine the 35 to 44 and the 45 to 54 cohorts); and (iii) 55 or older (i.e., keep this cohort as is). These latter three categories paralleled the younger, middle-aged and older working-age populations, respectively. There were six possible choices for the highest level of education completed: (i) grade school (i.e., through U.S. grade 8); (ii) some high school; (iii) high school (i.e., completed all of grades 9 through 12); (iv) some college; (v) college (i.e., a college degree was completed, though the survey questionnaire made no distinction between community and four-year colleges); and (vi) postgraduate (no distinction was made between Master's or Doctorate degrees). There were zero or near-zero proportions for the first three educational level categories, especially for CCAs. As zero proportions can be problematic for model fitting (Agresti 2010), the six original education levels were collapsed to the following three categories for this analysis: (i) high school or less (i.e., combine grade school, some high school, and high school); (ii) college (i.e., combine some college and college); and (iii) postgraduate (i.e., leave this category as is).

Our interest was to detect how perceptions and fungicide use varied by state (i.e., if there were regional differences), job type (CG or CCA), cohort, and educational level. Regression models were fit to survey responses as a function of state, job type, age and education as the primary predictors. For certain questions, additional predictors were included based on hypothesized associations (e.g., perception of disease importance is associated with the perceived importance of foliar fungicides to successful maize production). Binary survey responses ("Yes" or "No") were fit by logistic regression modeling. Survey questions which had three or more ordinal response categories (e.g., questions 1 and 2) were fit by the proportional odds version of the cumulative logit model (Agresti 2010). In all models, state $=$ IL, age $=55$ or older, and education $=$ college were used as the baseline factor levels (Hilbe 2009). Setting IL as the baseline for state was arbitrary. However, the eldest cohort was chosen as the baseline as representative of the group with the most farming and consulting experience. Collegelevel education was used as the baseline for educational level, as most CCAs and CGs had at least some level of college experience.

Predictors were considered as being associated with the response based on the joint examination of the fitted parameter's magnitude, the estimated variance and the Wald-type $95 \%$ confidence interval (CI) for the parameter. We deemphasized interpretations of significance based solely or largely on $P$ values (Madden et al. 2015). The interpretation of fitted logistic and proportional odds models was in terms of estimated odds ratios ([Szumilas 2010]; see also the Appendix) which were reported followed by their 95\% CIs (in brackets).

\section{RESULTS}

Importance of diseases and foliar fungicides in maize production. Weeds were regarded as the most important of the three biological agents, followed by insects and then diseases. Weeds were regarded by $90 \%$ of CCAs and CGs as being "Very important" or "Extremely important" to their perceived yield loss in maize, whereas for insects this estimate fell to $75 \%$ and further to $68 \%$ for diseases.

There were perceptional differences between CCAs and CGs in the importance placed on diseases regarding yield loss (Fig. 1). The odds of CGs classifying diseases as "Extremely important" versus the other categories combined were $1.89(1.20,2.96)$ times the odds of CCAs making the same classification. Likewise, there were 
differences among states in the ascribed importance of diseases to maize yield loss. In WI and $\mathrm{OH}$, the odds of classifying diseases as "Extremely important" versus all other categories combined were $0.39(0.20,0.75)$ and $0.5(0.25,0.99)$ times the odds of doing so in IL, respectively. That is, CCAs and CGs in $\mathrm{OH}$ and WI regarded diseases as being of lesser importance to maize yield loss than did their colleagues in IL (Fig. 1). Perceptions of the importance of diseases to maize yield loss did not differ by age or education.

In the second question, 13 factors were queried as to their importance to successful maize production. Four factors, all related to yield and profit, were regarded by more than $80 \%$ of CCAs and CGs as being "Very important" or "Extremely important" (Fig. 2). Hybrid disease resistance was also a factor that was regarded as highly important, more so by CGs than by CCAs. The odds of CGs regarding disease resistance to be "Extremely important" versus all other response categories combined were $1.72(1.12,2.63)$ times the respective odds for CCAs.

Foliar fungicides were perceived as being "Very important" or "Extremely important" by $23.9 \%$ of CCAs and CGs (Fig. 2). CCAs and CGs in $\mathrm{OH}$ and in WI particularly were less likely to regard foliar fungicides as being important to successful maize production. The odds of CCAs and CGs in $\mathrm{OH}$ regarding foliar fungicides to be "Extremely important", versus all other response categories combined, were $0.52(0.26,1.02)$ times the odds for CCAs and CGs in $\mathrm{IL}$; and for WI the respective odds were $0.35(0.17,0.71)$.

The importance of diseases to perceived yield loss (Fig. 1) influenced the perceptions of disease resistance and foliar fungicides to successful maize production (Fig. 3). If diseases were held to be of "High importance" to yield loss, then the odds of disease resistance being of "High importance" (compared with lesser importance) to successful maize production were $11.7(3.8,35.9)$ times the respective odds for those who held disease to be of "Low importance" to yield loss (Fig. 3). Similarly, if one held diseases to be of "High importance" to yield loss, then the odds of foliar fungicides being of "High importance" to successful maize production were $6.3(2.2,18.0)$ times the odds for those who held disease to be of "Low importance" to yield loss (Fig. 3).

Fungicide use. During 2005 to 2009, 73.3\% of CCAs recommended to their clients that a foliar fungicide be used on maize fields. Among CGs, $35.3 \%$ overall sprayed foliar fungicides on their maize (Fig. 4A). On average, the proportion of CCAs who had recommended spraying was 2.1 times the proportion of CGs who did spray. We fit a logistic regression model with foliar fungicide use (or recommendation) as the response ("Yes", "No"), and job type, state, education level, age, and importance of foliar fungicides for successful maize production ("High", "Intermediate", and "Low" importance) as predictors, including interaction terms between job type and state (based on Figure 4A suggesting that WI CCAs were less likely to recommend spraying than CCAs in the other three states). The odds of WI CCAs recommending foliar fungicide use on maize was $0.26,0.21$, and 0.32 times the odds of IL, IA, and $\mathrm{OH}$ CCAs doing so, respectively. As expected, CCAs and CGs who regarded foliar fungicides to be important in successful maize production were more likely to recommend spraying or to spray. Among those who viewed foliar fungicides as being of "High importance" to successful maize production, the odds of spraying (or recommending spraying) during 2005 to 2009 were 8.03 (3.42, 18.86) times the odds of spraying (or recommending spraying) among those who viewed foliar fungicides as being of "Low importance" to successful maize production.

Foliar fungicide usage in hybrid maize production was rare prior to 2000 (Fig. 4B) among those CCAs and CGs who had

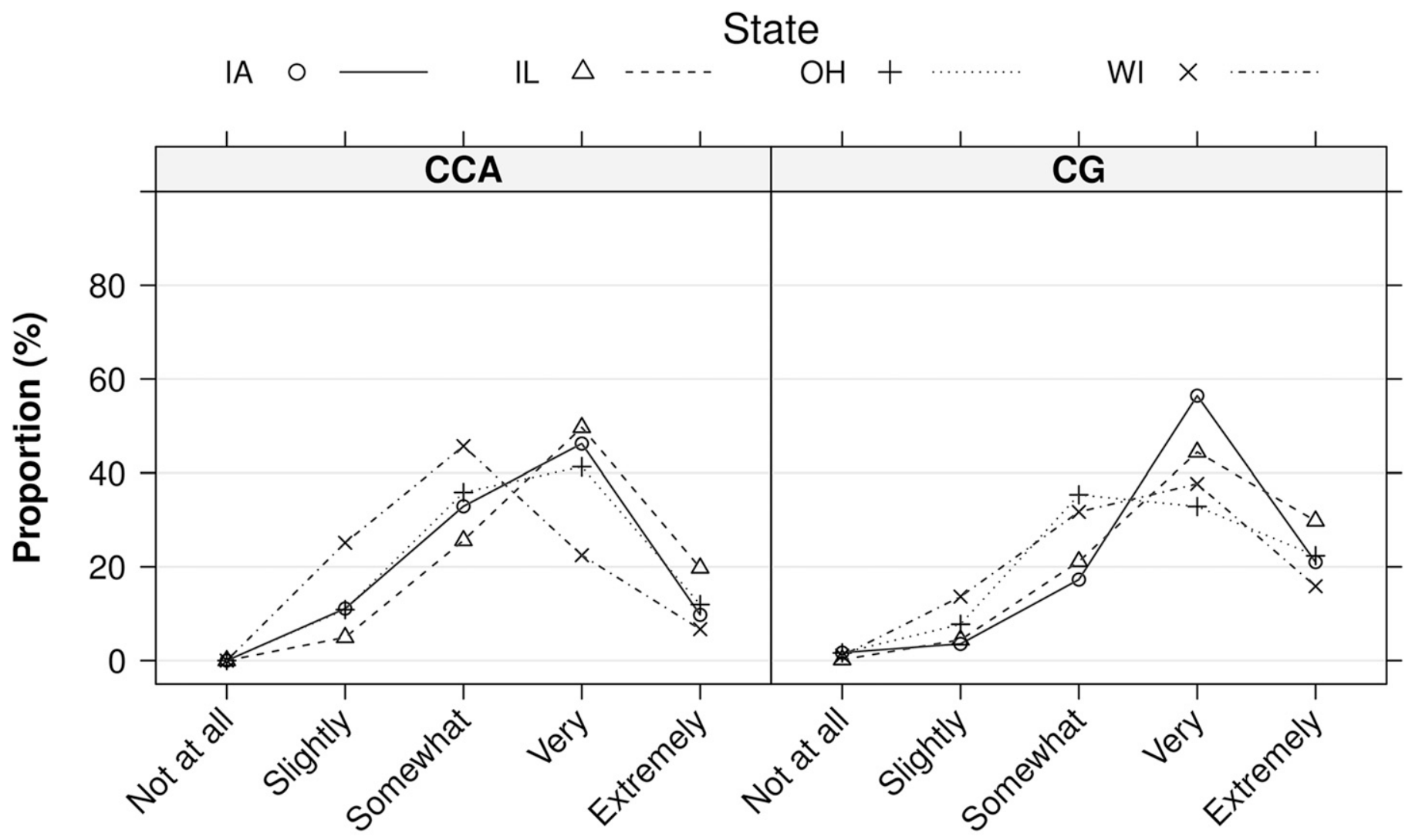

Importance of diseases to maize yield loss

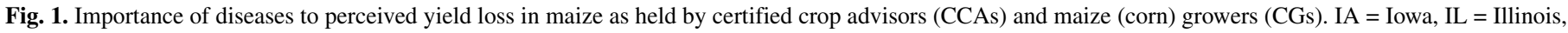
$\mathrm{OH}=$ Ohio, WI = Wisconsin. 
recommended or sprayed them during 2005 to 2009 . The 10 years after 2000 saw an approximately exponential increase in foliar fungicide use or recommendation, with adoption apparently having peaked by 2008. Among those who had recommended or used foliar fungicides between 2005 and 2009, 68.6\% of CCAs had recommended using a foliar fungicide for the first time, and $84.2 \%$ of CGs had used a foliar fungicide in maize production for the first time during this period.

Among those CCAs who had recommended spraying foliar fungicides during 2005 to $2009,98 \%$ had recommended making applications to grain, $35.7 \%$ to seed crops, and $24.3 \%$ to silage maize. For those CGs who did spray foliar fungicides during 2005 to $2009,94.1 \%$ made those applications to grain maize, $24.8 \%$ made them to seed crops, and $27.7 \%$ sprayed silage maize. That is, foliar fungicide use was mainly on maize for grain. The one anomaly was a relatively high proportion of CCAs in WI (out of those who had advised spraying maize during 2005 to 2009) who recommended applying foliar fungicides to silage maize: $76.5 \%$ had done so.

Headline was the main product of choice among CGs and CCAs who had sprayed (or recommended spraying) maize with foliar fungicides during 2005 to 2009 . Overall, $85.6 \%$ of those CCAs and CGs recommended or used Headline (pyraclostrobin), whereas that estimate was $49.1 \%$ for Quilt (azoxystrobin + propiconazole), $44.9 \%$ for Stratego (trifloxystrobin + propiconazole), and $36.7 \%$ for Quadris (azoxystrobin). The estimates were not statistically different by state (95\% confidence intervals for the odds ratios included one). The survey questionnaire did not ask about rates of application. However, we assumed that the standard labels were followed.
When conducting foliar fungicide applications in 2009, $51.3 \%$ of CCAs and $13.9 \%$ of CGs used untreated check strips for comparison of fungicide treatment effects. The general preference was for spraying the entire field, but leaving an untreated strip (either at one end or through the center of the field) immediately adjacent to fungicide-treated areas, presumably to facilitate visual comparison of the treated and untreated sections.

Perceived response to foliar fungicides. CCAs and CGs were asked if they had measured a positive (negative) yield response upon the application of a foliar fungicide, and if they did, to indicate the average gain (loss) in bushels per acre. Conditional on having sprayed (or recommended spraying) a foliar fungicide during 2005 to $2009,94.4 \%$ of CCAs and $65.1 \%$ of CGs realized a positive yield response in maize. There were no appreciable differences among the four states (95\% confidence intervals for the odds ratios included one). The yield gain most frequently reported (by both CCAs and CGs) was 0.31 to 0.57 metric tons per ha ( 5 to 9 bushels per acre; Fig. 5A). Foliar fungicides were estimated to improve maize yield by $4.08 \%$ (95\% CI of $3.56 \%$ to $4.60 \%$ ) per year on average. The average yield increase, conditional on having applied a foliar fungicide and observed a yield gain, was 0.47 tons per ha (95\% CI of 0.41 to 0.53 tons per ha), or 7.46 bushels per acre (95\% CI of 6.51 to 8.42 bushels per acre).

However, CCAs and CGs did not always experience a yield gain after spraying foliar fungicides. Across all four states, $47.4 \%$ of CCAs and $25.6 \%$ of CGs who had sprayed (or recommended spraying) during 2005 to 2009 had observed a negative yield response. The most-often perceived yield loss was 0.06 to 0.25 tons per ha (1 to 4 bushels per acre; Fig. 5B).

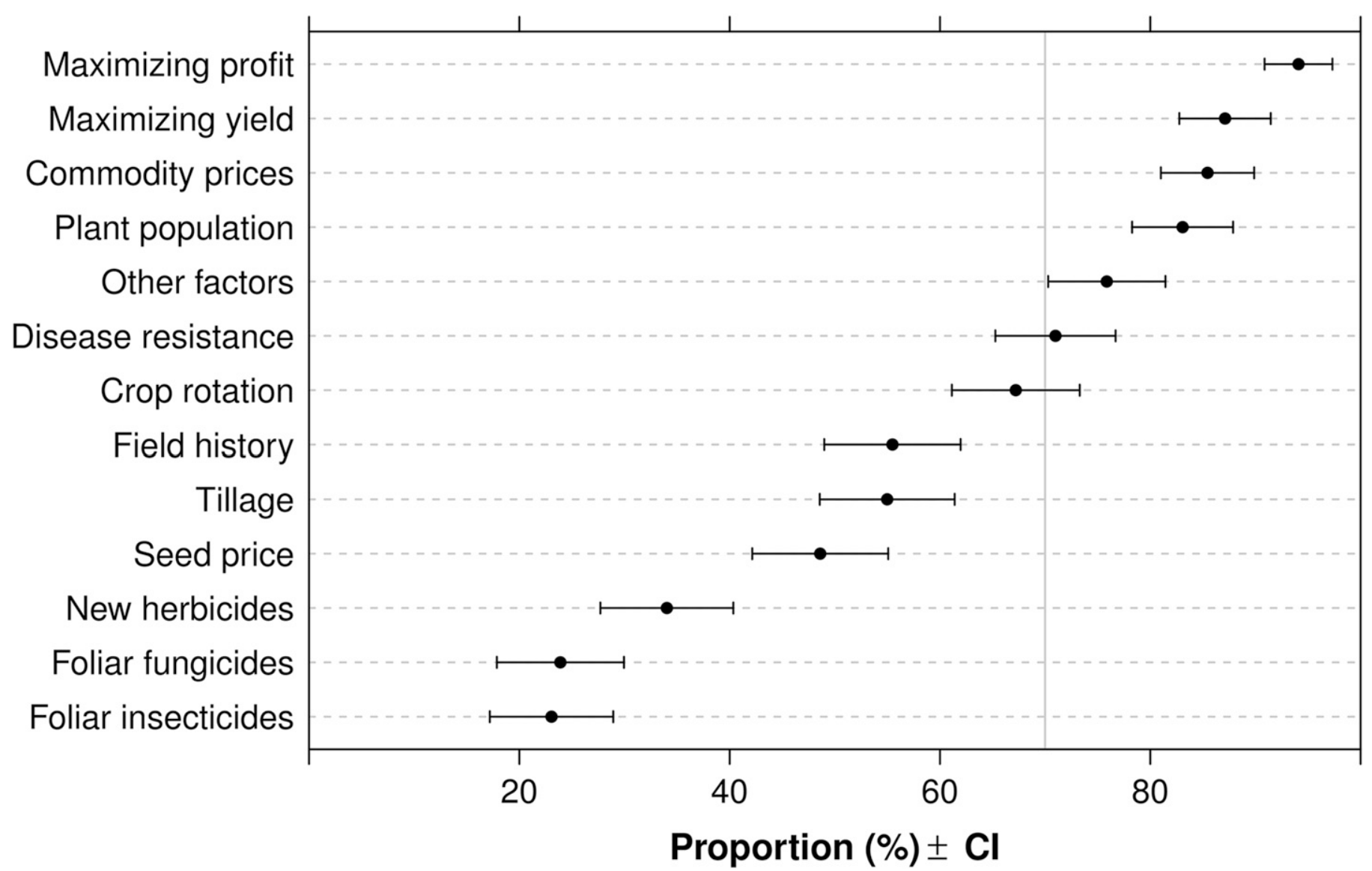

Fig. 2. Proportions of certified crop advisors and maize growers who perceived 13 queried factors as being very or extremely important to successful maize production. "Other factors" included, inter alia, the use of Roundup Ready seed, corn rootworm control, and the use of Bt traits. The vertical gray line is at $70 \%$. Error bars indicate the $95 \%$ confidence intervals (CIs) associated with each point estimate. 
On-farm trials. In 2009, $65.4 \%$ of CCAs and $24.1 \%$ of CGs had coordinated or had done some type of on-farm trial (hybrid, seed treatment, herbicide, insecticide or foliar fungicide). The younger cohorts were more likely to engage in on-farm trials: the odds of those aged 34 or younger doing on-farm trials was 4.91 $(1.25,19.25)$ times the odds of those aged 55 or older doing on-farm trials. Testing of hybrids was the most popular trial type, with $94.4 \%$ of CCAs and CGs who did trials in 2009 having done this type of trial. Foliar fungicide trials were the next most popular type of trial (76.4\% of CCAs and $44.4 \%$ of CGs, among those who did trials in 2009). The odds of having done fungicide trials in 2009 if one perceived foliar fungicides as being of "High importance" to successful maize production were $4.85(1.08,21.86)$ times the odds of having done fungicide trials in 2009 if one perceived foliar fungicides as being of "Low importance" to successful maize production. Within the group of CCAs who did foliar fungicide trials in 2009, 62.1\% replicated their treatments (corresponding estimates for CGs were imprecise). Three replicates were used on average.

Cost of fungicide treatments. CGs were asked how much they were willing to spend per acre on foliar fungicides in 2009, and CCAs were asked how much their clients were willing to spend per acre on foliar fungicides in 2009. CCAs believed that CGs were willing to spend more on foliar fungicides than CGs indicated they actually were. For example, $20.6 \%$ of CCAs thought their clients were willing to spend $\$ 61.78$ or more per ha ( $\$ 25$ or more per acre) on foliar fungicides, whereas only $2.2 \%$ of CGs were willing to spend that much (Fig. 6). The odds of CGs being willing to spend $\$ 61.78$ or more per ha on fungicides compared with less were $0.27(0.16,0.45)$ times the odds that CCAs thought their clients were willing to spend $\$ 61.78$ or more per ha on fungicides compared with less. Having used foliar fungicides on maize during 2005 to
2009 had an influence on the amount CCAs and CGs were willing to spend on foliar fungicides. For those who had sprayed fungicides in the last 5 years, the odds of being willing to spend $\$ 61.78$ or more per ha on fungicides compared with less were $5.2(2.8,9.6)$ times the odds for those who did not spray fungicides being willing to spend $\$ 61.78$ or more per ha compared with less. CCAs from WI did not think their clients were willing to spend much on foliar fungicides in 2009 compared with CCAs from the other states (Fig. 6).

\section{DISCUSSION}

Plant pathologists were concerned about the rapid increase in the use of foliar fungicides in U.S. maize production during the decade beginning with the year 2000 compared with years prior when spraying maize with fungicides was confined mainly to high-value seed production (Wegulo et al. 1998). Our survey of Midwestern CCAs and CGs across IA, IL, OH, and WI confirmed that the use of foliar fungicides in maize was indeed rare before 2000, and rose rapidly between 2000 and 2009; the majority of CGs and CCAs were first-time users or recommenders. However, foliar fungicide use was the second-to-last factor (among those factors queried in the survey) in importance to maize production, and therefore conflicted with the increased usage on maize from 2000 onwards, especially after considering that changes to crop production practices tend to be adopted slowly (Sherman and Gent 2014). Yet on the other hand, one may not be surprised that CCAs began recommending (and CGs began using) foliar fungicides from 2000 through 2009, given the confluence of several influential factors including greater crop value, QoI fungicides registered for maize, more available fungicide products, and plant health benefit marketing. CCAs and CGs both placed high importance on maximizing profit, which is a

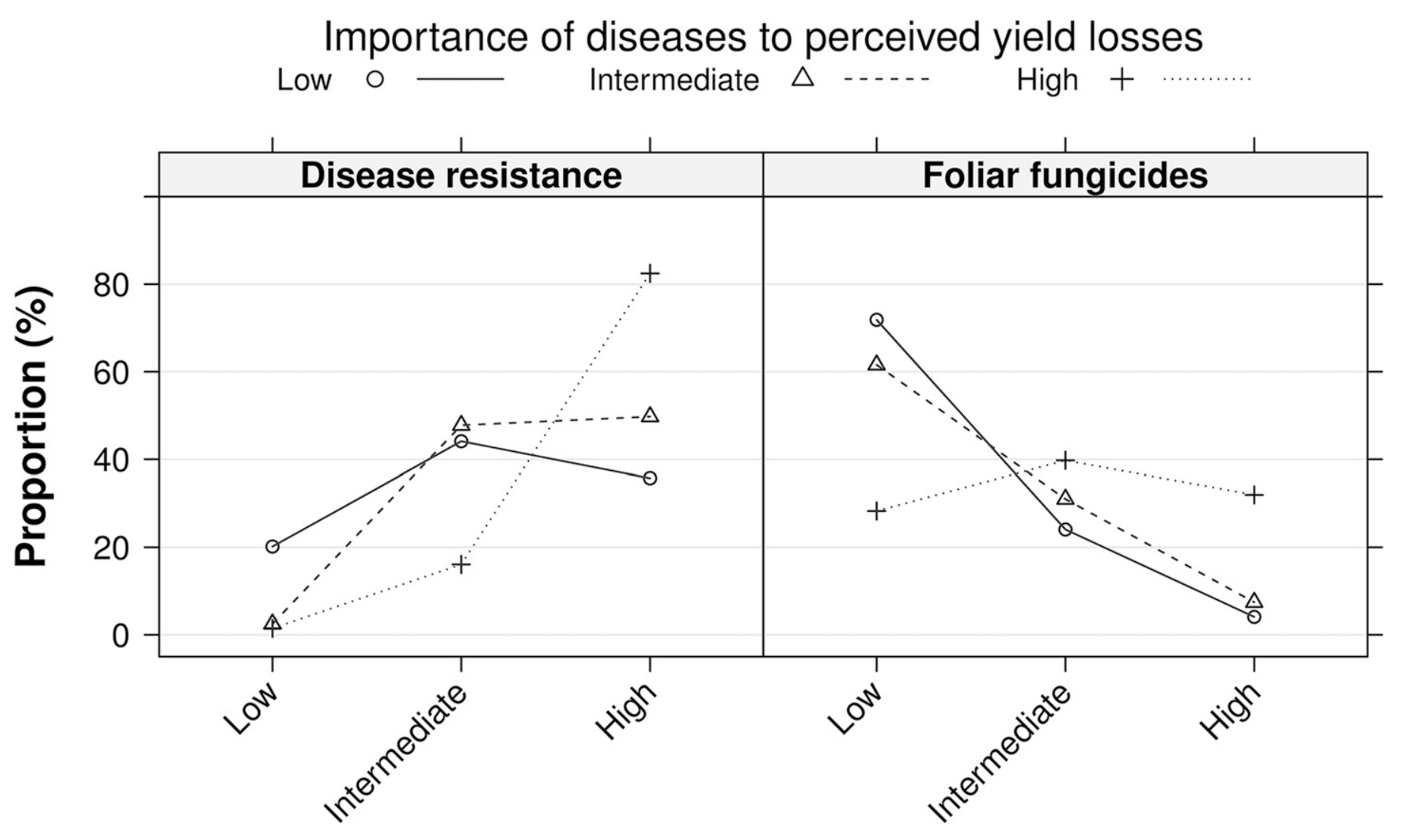

Importance of disease resistance and foliar fungicides

Fig. 3. Importance of disease resistance and foliar fungicides to successful maize production, conditional on the importance of diseases to perceived yield loss. 
function of plant population, attained yield and commodity price. Growers as a whole struggle particularly with balancing the conflicting roles of environmental steward and successful businessperson, the latter's success being measured by the achieved profit margin (Comito et al. 2013). In reality, short-term profit-making trumps the environmental stewardship role (Comito et al. 2013). In many situations, fungicide applications may not correspond with disease risk at all, because they are viewed as a form of insurance (van der Waals et al. 2016). Moreover, the primacy of foliar fungicides as a disease control measure is evolving to include generalized plant health benefits (Werts and Green 2013), which may be perceived as green leaf longevity and improved stalk strength in maize (Byamukama et al. 2013; Kalebich et al. 2017). Given the purported plant health benefits due to fungicides, one may speculate that CCAs and CGs viewed the application of fungicides to maize as a win-win hedge against disease risk uncertainty. Even so, CCAs drew on their own empirical observations, as just over $50 \%$ of those who recommended foliar fungicides used some form of check strip in treated fields in 2009 , and $76 \%$ of CCAs who did field testing in 2009 included fungicide trials.

Within the larger spectrum of biotic pests, CCAs and CGs regarded diseases to be of lesser importance than either weeds or insects, which was consistent with previous findings (Aref and Pike 1998; Gibson et al. 2005; Oerke 2006). Nevertheless, over 60\% of CCAs and CGs perceived diseases to be extremely important to maize yield loss, and CGs were more inclined to that perception than CCAs. Hybrid disease resistance, though not rated as highly as the profit-motivated factors, was also perceived as being very important to successful maize production, and suggested that CCAs and CGs used disease resistance when available in their preferred hybrids. If diseases were regarded to be of high importance to maize yield loss, then CCAs and CGs were more likely to ascribe higher importance to hybrid resistance as a factor in successful maize production. Given the importance placed on hybrid resistance, it is unlikely that IPM principles concerning maize disease management were discarded during 2005 to 2009.

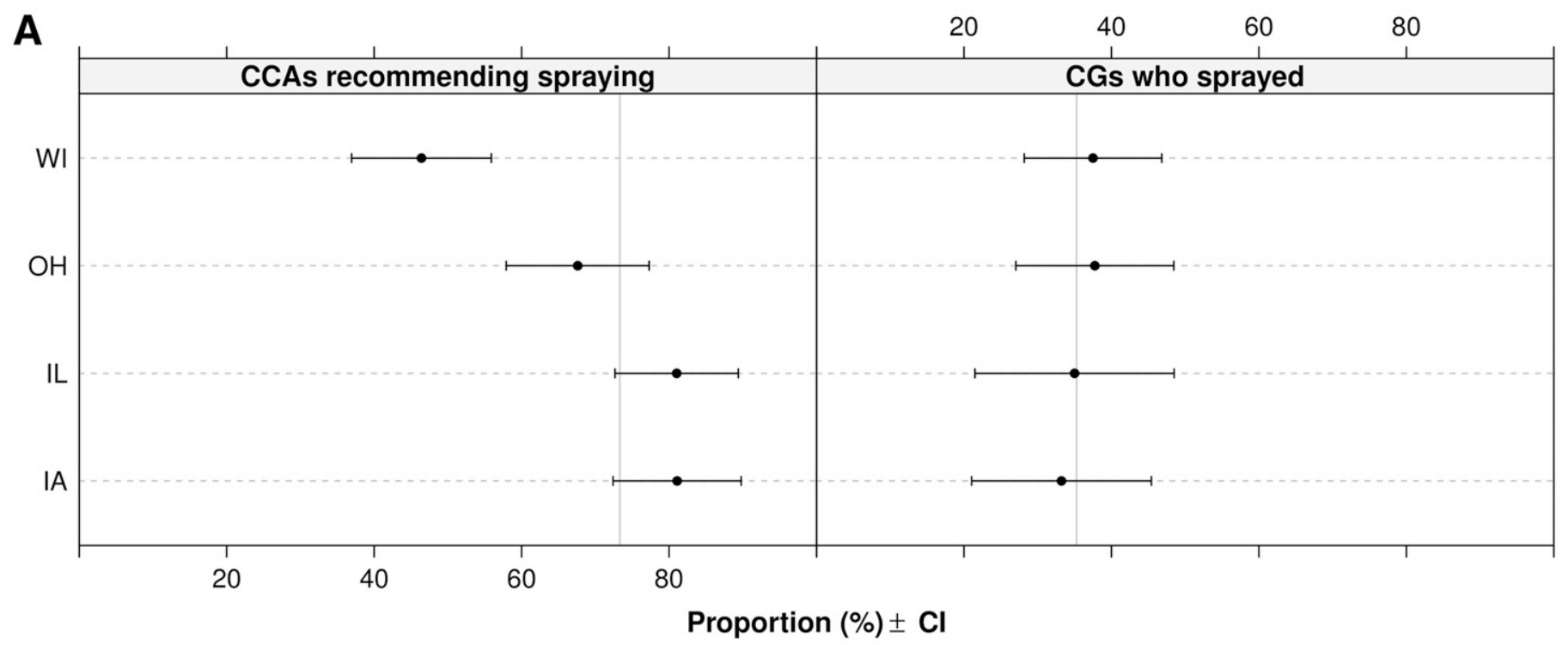

B

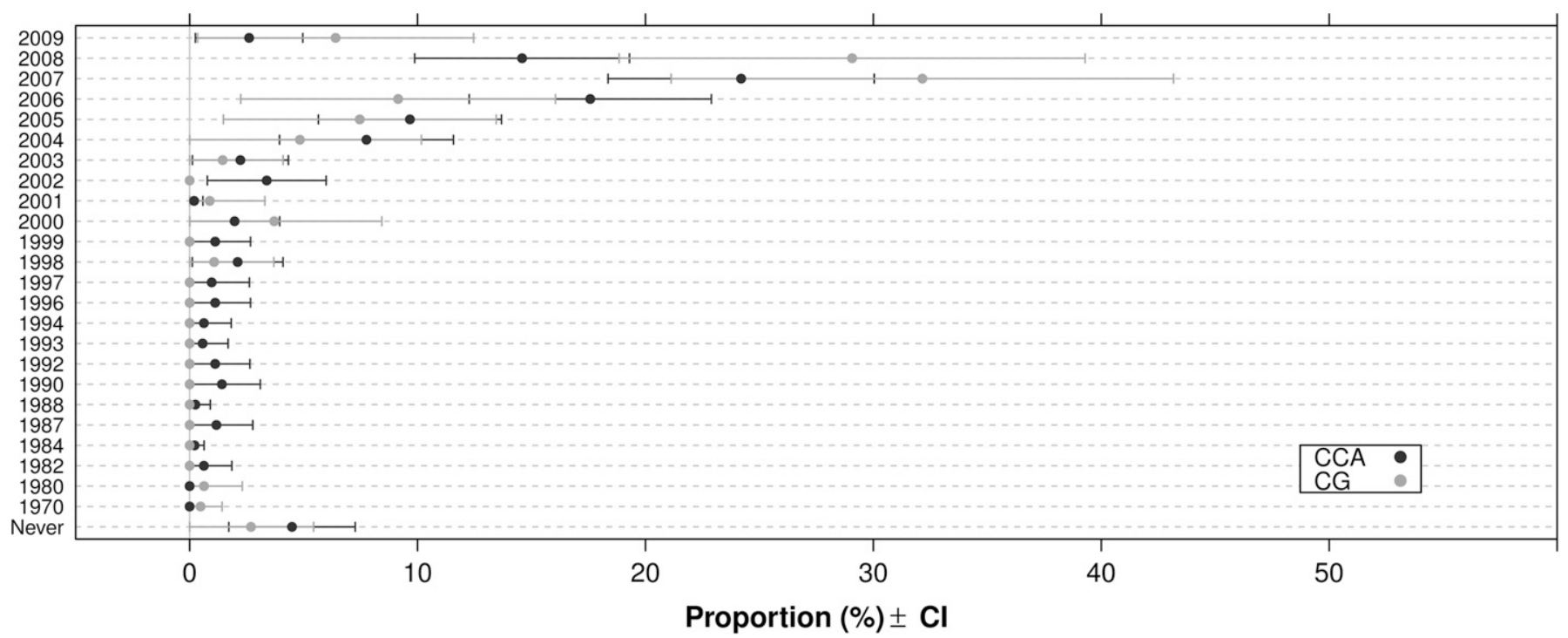

Fig. 4. A, Proportions of certified crop advisors (CCAs) who recommended spraying maize with foliar fungicides and the proportions of maize growers (CGs) who sprayed their maize with foliar fungicides during 2005 to 2009. IA $=$ Iowa, IL = Illinois, OH = Ohio, WI = Wisconsin. The vertical gray lines are the overall averages for CCAs (73.3\%) and CGs (35.3\%). B, First year of foliar fungicide use by CGs or recommended use by CCAs in hybrid maize production, conditional on having recommended or sprayed foliar fungicides during 2005 to 2009. In both panels, the error bars indicate the 95\% confidence intervals (CIs) associated with the point estimates. 
Rather, growers tend to adopt some components of IPM but not all of it (Puente et al. 2011; Sherman and Gent 2014). Hybrid trials were the most popular type of trial reported by survey respondents, not fungicide trials.

Diseases were not regarded with the same importance across the four states. They were perceived as being of lesser importance in $\mathrm{OH}$ and WI, which was reflected in lower ascribed importance of foliar fungicides to successful maize production in those two states compared with IA and IL. There may have been lower foliar disease prevalence or outbreaks in maize in $\mathrm{OH}$ and WI during 2005 to 2009; or these latter two states may in general experience less frequent maize disease epidemics overall. Encouragingly, later maize disease surveys accounted for potential regional differences suggested by the current survey findings (Mueller et al. 2016).

The survey data supported the contention that the use of foliar fungicides in maize had been extended from hybrid seed production to more widespread use in grain production. At first the relatively high proportion of WI CCAs who had recommended spraying silage maize was puzzling, until we became aware of an article on the Pioneer website (https://www.pioneer.com/home/site/us/silagezone/corn_silage_grow/fungicidesworthcost/) that addressed foliar fungicides in silage maize. The article had been reprinted from the WI-based Hoard's Dairyman (https://hoards.com/article-5395-arecorn-fungicides-worth-the-additional-cost-.html). In this article, there is what can be regarded as an influential message stating the following: "A 2007 field trial conducted by University of Wisconsin
Extension specialists showed that fungicide treatment resulted in a 0.7 ton gain in silage dry matter yield and a $1.9 \%$ boost in starch content. While these improvements were not statistically significant, they do appear to be biologically and economically encouraging." It therefore appears WI-based CCAs were aware of this article and were projecting the reported findings in their recommendations. Notwithstanding, the topic of foliar fungicide effects on silage maize and dairy production has seen recent interest (Haerr et al. 2015, 2016; Kalebich et al. 2017).

CCAs and CGs used all four of the queried fungicide products, which represented QoI chemistries alone or in combination with a demethylation inhibitor. Headline was by far the product used or recommended most frequently. CCAs and CGs should be made aware of the potential of fungicide resistance (Bradley and Pedersen 2011), how to manage the risk of fungicide resistance development (Vincelli 2002), and wider ecological consequences (Pretty 2008). Our survey did not ask about the number of foliar fungicide applications made to a crop within one season, or whether chemistries were rotated within or across consecutive seasons. However, the ARMS estimated that in 2010 one to two sprays were applied when fungicides were used in maize in IA and IL.

CCAs overestimated how much their clients were willing to spend on foliar fungicides in 2009. About $60 \%$ of CGs were willing to spend no more than $\$ 37.07$ per ha ( $\$ 15$ per acre) on foliar fungicides in 2009. Additionally, the fact that WI CCAs did not believe their clients would spend much on foliar fungicides in 2009

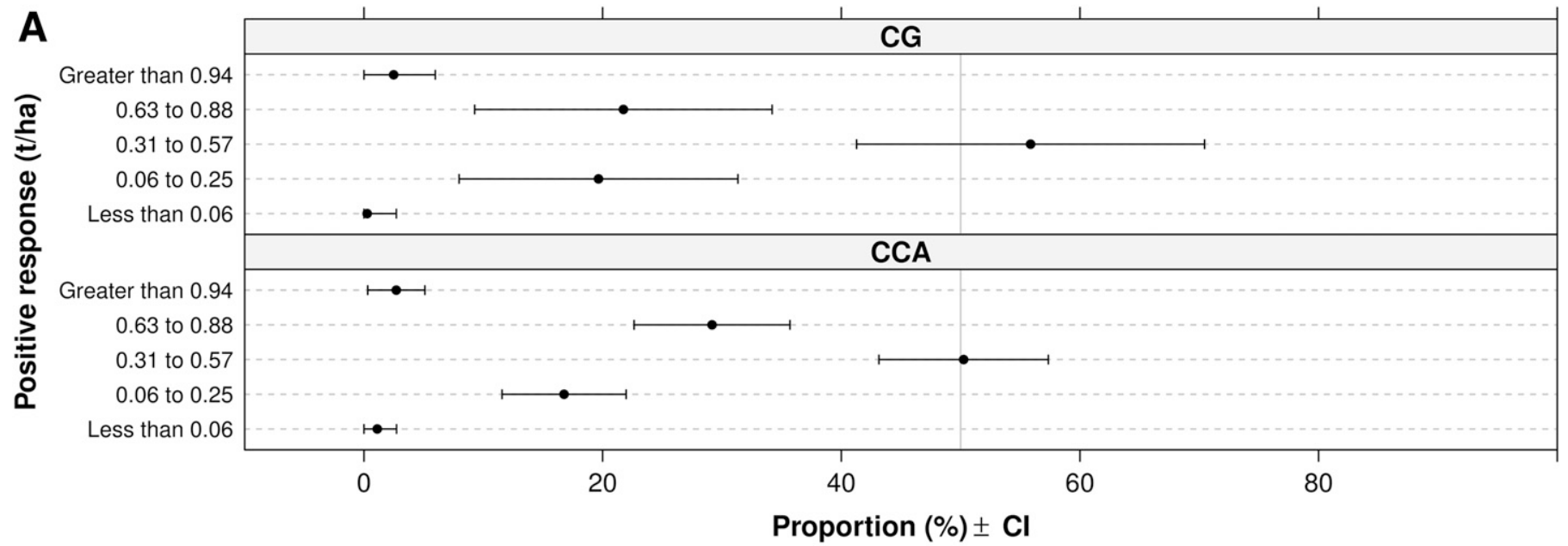

B

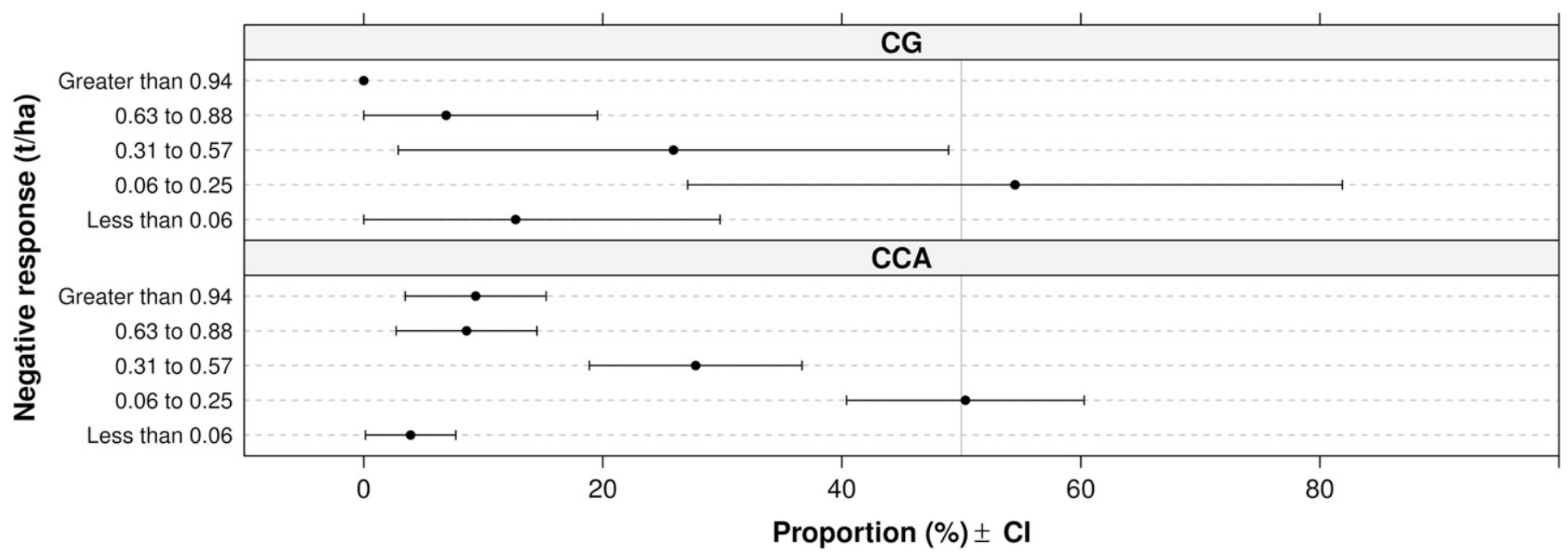

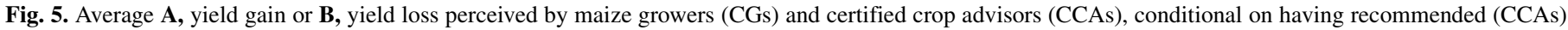
or sprayed (CGs) foliar fungicides during 2005 to 2009 . The vertical gray lines are at $50 \%$. Error bars for the $95 \%$ confidence intervals (CIs) are shown. 
perhaps reflected the lower importance given to diseases in that state. The estimated amount CGs were willing to spend per ha on foliar fungicides was more to the lower end of the $\$ 40$ to $\$ 95$ per ha ( $\$ 16.19$ to $\$ 38.45$ per acre) (Paul et al. 2011) and the $\$ 59.31$ to $\$ 69.19$ per ha (\$24 to $\$ 28$ per acre) (Tedford et al. 2017) fungicide application costs assumed in two previous studies. Different assumptions on fungicide application costs will affect the estimated probability of recuperating the costs of such applications in maize (Paul et al. 2011; Tedford et al. 2017), but more importantly cost may determine whether CGs initiate spraying at all.

Among CCAs who had sprayed foliar fungicides during 2005 to 2009 , the majority ( $94 \%$ ) perceived a positive yield response. The average yield gain of 0.47 tons per ha was greater than a previously estimated break-even point of 0.38 tons per ha (Wise and Mueller 2011). University trials indicated that $48 \%$ of fungicide treatments in maize met or exceeded the 0.38 tons per ha break-even point, which was consistent with the 40 to $60 \%$ of CGs and CCAs who estimated an average yield gain of 0.31 to 0.57 tons per ha in the current survey. CGs were more skeptical (or conservative in their estimates) than CCAs, as only two-thirds of CGs who used foliar fungicides during 2005 to 2009 perceived a positive yield response. The average yield increase estimated from the survey data were well within the reported ranges observed with university trials (Paul et al. 2011), somewhat above the small-plot estimates of yield gain reported by Tedford et al. (2017), and well-below the estimates given for large-plot and commercial-strip trials (Tedford et al. 2017). CGs and CCAs did not always see a yield gain in response to foliar fungicides; almost half $(47.4 \%)$ of CCAs and $25.6 \%$ of CGs had observed a negative yield response. These latter estimates were consistent with quantitative analyses of yield responses to foliar fungicides in maize (Paul et al. 2011), in which a negative yield response had occurred in 26 to $48 \%$ of the studies.
Although CGs were more likely than CCAs to give higher importance to diseases as a yield-limiting factor, they were not as embracing of foliar fungicides (compared with CCAs), and were more skeptical (Sherman and Gent 2014) about perceived yield benefits. Foliar fungicide trials were done mainly by CCAs with a college-level education; but were more likely to be done by CCAs who perceived that foliar fungicides were important to successful maize production. CCAs are influencers within the agricultural community via their extended networks, and there is interest in how CCAs influence the perceptions and practices of their grower clients (Hillis et al. 2016). The question of how much influence CCAs had on CGs with respect to the adoption of foliar fungicides in maize remains an open question.

By properly weighting estimates according to the survey design, we could draw inferences at the population level (i.e., the populations of CCAs and CGs in IA, IL, OH, and WI). Our approach to survey analysis, though standard among larger-scale surveys (such as the ARMS) is still rare among plant pathologists, who tend to present survey results as raw estimates (e.g., percent of fields with disease out of $n$ fields sampled) without consideration of the target population or survey sampling scheme. A more thorough understanding of survey methodology and analysis (Heeringa et al. 2010; Lumley 2010; Michel et al. 2017), along with an appreciation of sample and target populations, will undoubtedly advance the discipline, especially in the estimation of disease at the state or regional scale.

\section{APPENDIX}

The material in this section largely paraphrases Agresti (2010). Consider a survey question having $c$ response categories with probabilities $\pi_{1}, \ldots, \pi_{c}$. For survey question $1, c=5$, for example. The cumulative logits are given by

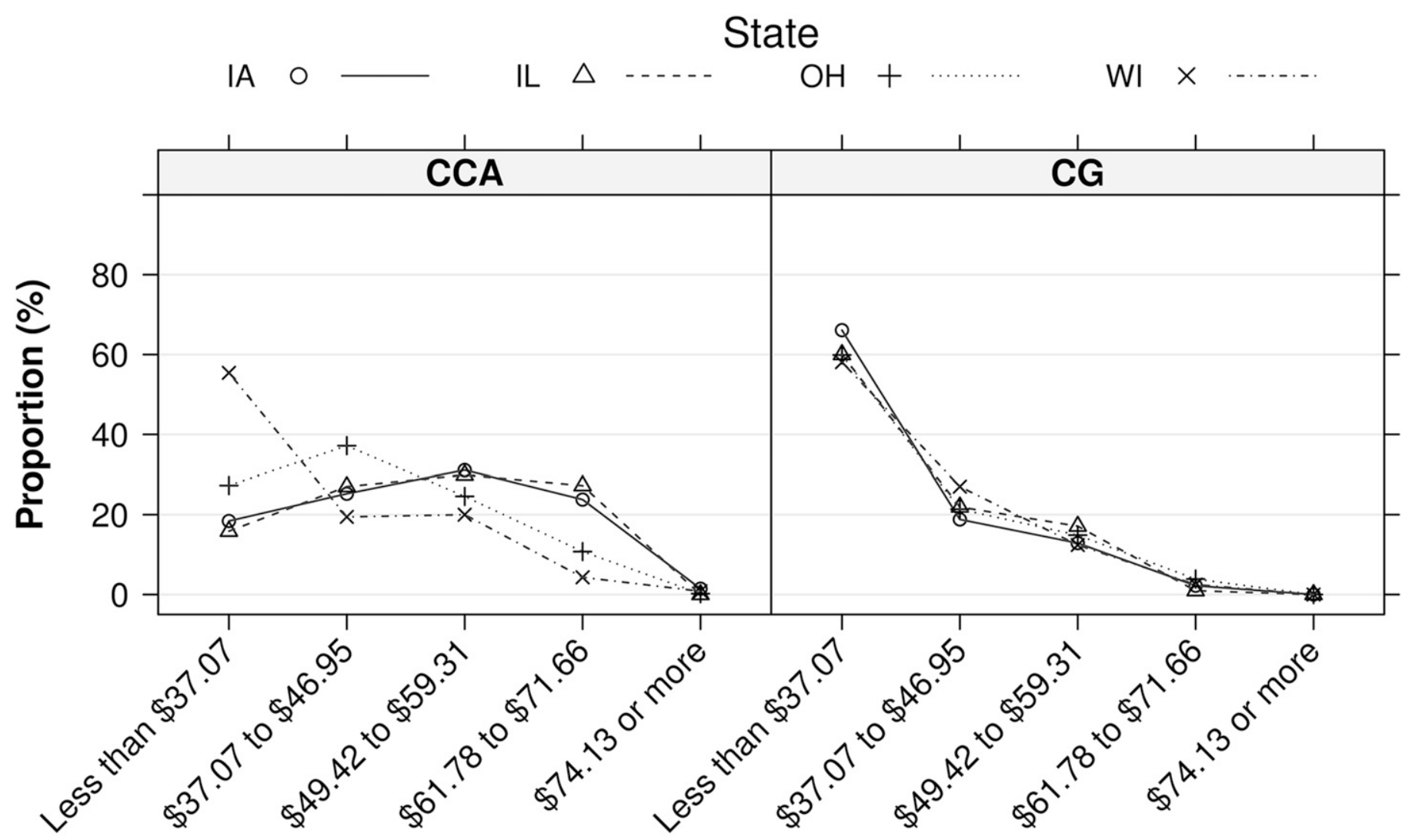

\section{Amount willing to spend on foliar fungicides (\$/ha)}

Fig. 6. The amount certified crop advisors (CCAs) and maize growers (CGs) were willing to spend on foliar fungicides on maize in 2009. 


$$
\operatorname{logit}[P(Y \leq j)]=\log \frac{P(Y \leq j)}{1-P(Y \leq j)}
$$

where the $j$ are cut-points defining the categories. (It may help the reader to visualize an underlying latent continuous scale [e.g., 0 to $100]$, with 0 to 20 representing category $1, \ldots, 80$ to 100 representing category 5.) Equation A1 is a generalization of the binary case for which there are of course two responses categories (e.g., "Yes" and "No") which are modeled by logistic regression. In the binary setting there is a single logit modeling the outcomes $Y \leq j$ and $Y>j$. With $c$ categories, Equation A1 encapsulates $c-1$ logits. To see this, suppose $c=4$. The three logits capture (i) $P(Y \leq 1)$ versus $P(Y>1)$, (ii) $P(Y \leq 2)$ versus $P(Y>2)$, and (iii) $P(Y \leq 3)$ versus $P(Y>3)$. Note that the right-hand side of Equation $\mathrm{A} 1$ is the log of the odds of $Y \leq j$.

When there are more than two response categories which are also ordered, we desire a model that not only models the outcome categories but also respects the intrinsic ordering of the categories. The cumulative logit model does both. As the current article deals with categorical predictors, consider a single predictor $x$ representing two levels of a factor, where $x=0$ for the first level of the factor (baseline) and $x=1$ for the second level of the factor. The cumulative logit model is

$$
\operatorname{logit}[P(Y \leq j \mid x)]=\alpha_{j}+\beta x, j=1, \ldots, c-1
$$

Equation A2 represents $c-1$ logistic curves or models encompassed in a single model. The single model is more parsimonious and easier to interpret than $c-1$ separate logistic regression models. Notice that each logit has its own intercept $\alpha_{j}$. It is a matter of straightforward algebra to show that $\operatorname{logit}[P(Y \leq j \mid x=1)]-$ $\operatorname{logit}[P(Y \leq j \mid x=0)]$ is

$$
\log \frac{P(Y \leq j \mid x=1) / P(Y>j \mid x=1)}{P(Y \leq j \mid x=0) / P(Y>j \mid x=0)}=\beta
$$

That is, $\beta$ is the $\log$ of the cumulative odds ratio. Furthermore, stemming from Equation A2, $\beta$ is the same for each of the $c-1$ logits, which is referred to as the proportional odds property. Exponentiating $\beta$ thus gives the ratio of the cumulative odds of $Y \leq j$ at $x=1$ to the cumulative odds of $Y \leq j$ at $x=0$.

\section{ACKNOWLEDGMENTS}

We thank the University of Wisconsin Survey Center for assistance with the survey design and administration.

\section{LITERATURE CITED}

Agresti, A. 2010. Analysis of Ordinal Categorical Data, 2nd Ed. John Wiley \& Sons, Inc., Hoboken, NJ.

Aref, S., and Pike, D. R. 1998. Midwest farmers' perceptions of crop pest infestation. Agron. J. 90:819-825.

Bradley, C. A. 2012. Factors considered when making corn foliar fungicide application decisions in Illinois. Journal of Extension 50:3RIB7. https:// www.joe.org/joe/2012june/rb7.php

Bradley, C. A., and Ames, K. A. 2010. Effect of foliar fungicides on corn with simulated hail damage. Plant Dis. 94:83-86.

Bradley, C. A., and Pedersen, D. K. 2011. Baseline sensitivity of Cercospora zeae-maydis to quinone outside inhibitor fungicides. Plant Dis. 95:189-194.

Byamukama, E., Abendroth, L. J., Elmore, R. W., and Robertson, A. E. 2013. Quantifying the effect of Pyraclostrobin on grain-fill period and kernel dry matter accumulation in maize. Plant Health Progress. doi.org/10.1094/ PHP-2013-1024-02-RS

Comito, J., Wolseth, J., and Morton, L. W. 2013. Stewards, businessmen, and heroes?: Role conflict and contradiction among row-crop farmers in an age of environmental uncertainty. Hum. Organ. 72:283-292.

Gibson, K. D., Johnson, W. G., and Hillger, D. E. 2005. Farmer perceptions of problematic corn and soybean weeds in Indiana. Weed Technol. 19:1065-1070.

Groves, R. M., and Lepkowski, J. M. 1985. Dual frame, mixed mode survey designs. J. Off. Stat. 1:263-286.
Haerr, K. J., Lopes, N. M., Pereira, M. N., Fellows, G. M., and Cardoso, F. C. 2015. Corn silage from corn treated with foliar fungicide and performance of Holstein cows. J. Dairy Sci. 98:8962-8972.

Haerr, K. J., Pineda, A., Lopes, N. M., Weems, J. D., Bradley, C. A., Pereira, M. N., Murphy, M. R., Fellows, G. M., and Cardoso, F. C. 2016. Effects of corn treated with foliar fungicide on in situ corn silage degradability in Holstein cows. Anim. Feed Sci. Technol. 222:149-157.

Heeringa, S. G., West, B. T., and Berglund, P. A. 2010. Applied Survey Data Analysis. Chapman and Hall/CRC, Boca Raton, FL.

Hilbe, J. 2009. Logistic Regression Models. CRC Press, Boca Raton, FL.

Hillis, V., Lubell, M., Kaplan, J., Doll, D., and Baumgartner, K. 2016. The role of pest control advisers in preventative management of grapevine trunk diseases. Phytopathology 106:339-347.

Ilbery, B., Maye, D., Ingram, J., and Little, R. 2013. Risk perception, crop protection and plant disease in the UK wheat sector. Geoforum 50:129-137.

Ilbery, B., Maye, D., and Little, R. 2012. Plant disease risk and groweragronomist perceptions and relationships: An analysis of the UK potato and wheat sectors. Appl. Geogr. 34:306-315.

Jirak-Peterson, J. C., and Esker, P. D. 2011. Tillage, crop rotation, and hybrid effects on residue and corn anthracnose occurrence in Wisconsin. Plant Dis. 95:601-610.

Kalebich, C. C., Weatherly, M. E., Robinson, K. N., Fellows, G. M., Murphy, M. R., and Cardoso, F. C. 2017. Foliar fungicide (pyraclostrobin) application effects on plant composition of a silage variety corn. Anim. Feed Sci. Technol. 225:38-53.

Kish, L. 1965. Survey Sampling. John Wiley \& Sons, Inc., New York.

Latterell, F. M., and Rossi, A. E. 1983. Gray leaf spot of corn: A disease on the move. Plant Dis. 67:842-847.

Lipps, P. E. 1998. Gray leaf spot: A global threat to corn production. APSnet Features. doi.org/10.1094/APSnetFeature-1998-0598

Lumley, T. 2004. Analysis of complex survey samples. J. Stat. Softw. 9:1-19.

Lumley, T. 2010. Complex Surveys: A Guide to Analysis Using R. John Wiley \& Sons, Hoboken, NJ.

Lupo, C., Wilmart, O., Van Huffel, X., Dal Pozzo, F., and Saegerman, C. 2016. Stakeholders' perceptions, attitudes and practices towards risk prevention in the food chain. Food Control 66:158-165.

Madden, L. V., Shah, D. A., and Esker, P. D. 2015. Does the $P$ value have a future in plant pathology? Phytopathology 105:1400-1407.

Mallowa, S. O., Esker, P. D., Paul, P. A., Bradley, C. A., Chapara, V. R., Conley, S. P., and Robertson, A. E. 2015. Effect of maize hybrid and foliar fungicides on yield under low foliar disease severity conditions. Phytopathology 105:1080-1089.

Maye, D., Ilbery, B., and Little, R. 2012. Rationalising risk: Grower strategies to manage plant disease in the UK wheat and potato sectors. Geogr. J. 178: 338-347.

McRoberts, N., Hughes, G., and Savary, S. 2003. Integrated approaches to understanding and control of diseases and pests in field crops. Austral. Plant Pathol. 32:167-180.

Michel, L., Brun, F., and Makowski, D. 2017. A framework based on generalised linear mixed models for analysing pest and disease surveys. Crop Prot. 94:1-12.

Mueller, D. S., Wise, K. A., Sisson, A. J., Allen, T. W., Bergstrom, G. C., Bosley, D. B., Bradley, C. A., Broders, K. D., Byamukama, E., Chilvers, M. I., Collins, A., Faske, T. R., Friskop, A. J., Heiniger, R. W., Hollier, C. A., Hooker, D. C., Isakeit, T., Jackson-Ziems, T. A., Jardine, D. J., Kinzer, K., Koenning, S. R., Malvick, D. K., McMullen, M., Meyer, R. F., Paul, P. A., Robertson, A. E., Roth, G. W., Smith, D. L., Tande, C. A., Tenuta, A. U., Vincelli, P., and Warner, F. 2016. Corn yield loss estimates due to diseases in the United States and Ontario, Canada from 2012 to 2015. Plant Health Progress. doi.org/10.1094/PHP-RS-16-0030

Oerke, E.-C. 2006. Crop losses to pests. J. Agric. Sci. 144:31-43.

Paul, P. A., Madden, L. V., Bradley, C. A., Robertson, A. E., Munkvold, G. P., Shaner, G., Wise, K. A., Malvick, D. K., Allen, T. W., Grybauskas, A., Vincelli, P., and Esker, P. 2011. Meta-analysis of yield response of hybrid field corn to foliar fungicides in the U.S. Corn Belt. Phytopathology 101: $1122-1132$.

Paul, P. A., and Munkvold, G. P. 2004. A model-based approach to preplanting risk assessment for gray leaf spot of maize. Phytopathology 94:1350-1357.

Paul, P. A., and Munkvold, G. P. 2005. Regression and artificial neural network modeling for the prediction of gray leaf spot of maize. Phytopathology 95:388-396.

Pretty, J. 2008. Agricultural sustainability: Concepts, principles and evidence. Philos. Trans. R. Soc. B-Biol. Sci. 363:447-465.

Puente, M., Darnall, N., and Forkner, R. E. 2011. Assessing integrated pest management adoption: Measurement problems and policy implications. Environ. Manage. 48:1013-1023.

Romero Luna, M. P., and Wise, K. A. 2015. Timing and efficacy of fungicide applications for Diplodia ear rot management in corn. Plant Health Progress. doi.org/10.1094/PHP-RS-15-0010 
Rubin, D. R. 1987. Multiple Imputation for Nonresponse in Surveys. Wiley, New York.

Sarkar, D. 2008. Lattice: Multivariate Data Visualization with R. Springer, New York.

Sherman, J., and Gent, D. H. 2014. Concepts of sustainability, motivations for pest management approaches, and implications for communicating change. Plant Dis. 98:1024-1035.

Szumilas, M. 2010. Explaining odds ratios. J. Can. Acad. Child Adolesc. Psychiatry 19:227-229.

Tedford, E. C., Kriss, A. B., Geater, C., Saini, M., Battles, B., Smelser, R. B., and Fithian, W. A. 2017. Plot size can influence yield benefits from fungicides on corn. Crop Prot. 91:66-73.

van Buuren, S., and Groothuis-Oudshoorn, K. 2011. MICE: Multivariate imputation by chained equations in R. J. Stat. Softw. 45:1-67.

van der Waals, J. E., Steyn, J. M., Franke, A. C., and Haverkort, A. D. 2016. Grower perceptions of biotic and abiotic risks of potato production in South Africa. Crop Prot. 84:44-55.

Vincelli, P. 1999. Perceptions of fungicide use on corn, 1998. Kentucky Pest News Number 838.

Vincelli, P. 2002. Q $\mathrm{I}$ (strobilurin) fungicides: Benefits and risks. The Plant Health Instructor. doi.org/10.1094/PHI-I-2002-0809-02
Ward, J. M. J., Stromberg, E. L., Nowell, D. C., and Nutter, F. W., Jr. 1999. Gray leaf spot: A disease of global importance in maize production. Plant Dis. 83:884-895.

Wegulo, S. N., Martinson, C. A., Rivera-C, J. M., and Nutter, F. W., Jr. 1997. Model for economic analysis of fungicide usage in hybrid corn seed production. Plant Dis. 81:415-422.

Wegulo, S. N., Rivera-C, J. M., Martinson, C. A., and Nutter, F. W., Jr. 1998. Efficacy of fungicide treatments for control of common rust and northern leaf spot in hybrid corn seed production. Plant Dis. 82: 547-554.

Werts, P., and Green, T. 2013. University and industry scientists weigh in on fungicides for plant health in corn and soybeans. Crops \& Soils Magazine. doi: $10.2134 / \mathrm{cs} 2013-46-6-6$

White, I. R., Royston, P., and Wood, A. M. 2011. Multiple imputation using chained equations: Issues and guidance for practice. Stat. Med. 30: 377-399.

Wise, K., and Mueller, D. 2011. Are fungicides no longer just for fungi? An analysis of foliar fungicide use in corn. APSnet Features. doi:10.1094/ APSnetFeature-2011-0531

Zalucki, M. P., Adamson, D., and Furlong, M. J. 2009. The future of IPM: Whither or wither? Aust. J. Entomol. 48:85-96. 